\title{
OS ESPAÇOS AUTO-ORGANIZADOS E A PARTICIPAÇÃO DA MULHER NA EXTENSÃO
}

\author{
V. V. Girão $\operatorname{Chaves}^{1} \&$ L. C. Vieira ${ }^{2}$ \\ Graduanda em Direito pela Universidade Federal do Ceará (UFC) e bolsista do projeto de extensão Diálogos para Diversidade. E-mail: \\ vitoria virna@hotmail.com; ${ }^{2}$ Graduanda em Direito pela Universidade Federal do Ceará (UFC) E-mail: larissacarmuca@gmail.com
}

Artigo submetido em setembro/2018

\section{RESUMO}

A luta das mulheres pela ocupação dos espaços públicos no Brasil é um compromisso diário que incorpora o combate a uma cultura que viola e inferioriza as mulheres. Na violência contra a mulher há a violência visível, mais perceptível; e a violência simbólica, que consiste na reprodução de discursos e práticas opressoras que legitimam agressões mais graves. A violência simbólica é cotidiana, estando presente em todos os espaços ocupados por mulheres. Seja nas ruas ou na Universidade, nenhuma mulher está livre dos estereótipos e das definições sociais. Assim, o Centro de Assessoria Jurídica Universitária (CAJU), programa ao qual está vinculado o Diálogos para Diversidade, criou a Plenária de Mulheres, um espaço auto-organizado voltado ao combate ao machismo e à violência simbólica no núcleo, partindo da compreensão que o grupo, ainda que se aproxime das pautas feministas, não está isento da lógica patriarcal. Dentre as atividades preparadas estão a cartilha sobre assédio, o Cine Plenária, a campanha virtual pelas mulheres na política, a caixinha contra assédio na universidade e os grupos de estudo internos. O presente trabalho objetiva, então, apresentar as ações de extensão desenvolvidas pela Plenária de Mulheres. Utiliza-se a pesquisa bibliográfica e a observação participante, relatando as atividades organizadas e a contribuição do espaço para criar um ambiente menos opressor. Conclui-se, então, que os espaços auto-organizados contribuem para o combate às violações dentro dos projetos, além de fomentar ações que se estendam para fora do núcleo, debatendo temas presentes no cotidiano feminino e fortalecendo a luta das mulheres.

PALAVRAS-CHAVE: Plenária de Mulheres. Espaços auto-organizados. Violência Simbólica.Empoderamento.

\section{THE SELF-ORGANIZED SPACES AND THE PARTICIPATION OF WOMAN IN THE EXTENSION}

\begin{abstract}
The women fighting for the occupation of public spaces in Brazil is a daily commitment that incorporates the fight against a culture that violates and undermines women. In violence against women there is the visible violence; and the symbolic violence, which consists in the reproduction of discourses and oppressive practices that legitimize more serious aggressions. Symbolic violence is daily, being present in all spaces occupied by women. Whether on the streets or at the university, no woman is free from stereotypes and social definitions. Thus, the University Legal Advisory Center (CAJU), a program to which Dialogues for Diversity is linked, created the Women's Plenary, a self-organized space aimed at combating machismo and symbolic violence in the nucleus, starting from the understanding that the
\end{abstract}

group, even if it comes close to feminist guidelines, is not exempt from patriarchal logic. Among the activities prepared are the booklet on harassment, the Cine Plenary, the virtual campaign for women in politics, the box against harassment in the university and the internal study groups. The present work aims to present the extension actions developed by the Women's Plenary. Bibliographic research and participant observation are used, reporting on organized activities and the contribution of space to creating a less oppressive environment. It is concluded that self-organized spaces contribute to the fight against violations within the projects, as well as fostering actions that extend outside the nucleus, debating themes present in women's daily life and strengthening the women fighting.

KEYWORDS: Psychoanalytic clinic. Childhood. Adolescence. Diagnosis. Mental health. 


\section{INTRODUÇÃO}

A reivindicação das mulheres por respeito e por igualdade de gênero tomou, visivelmente, uma maior proporção nos últimos anos. Influenciadas, provavelmente, pela facilidade com que as informações são transmitidas na era digital, as pautas do movimento feminista alcançam um número cada vez maior de pessoas e são debatidas com maior frequência em todos os espaços, nas redes sociais, na universidade, no trabalho, na mídia, na arte, nas ruas e nos coletivos. Casos de violência contra a mulher atingem uma maior repercussão, causam indignação e a reprovação de homens e mulheres de todas as faixas etárias, e são responsáveis por reacender os debates sobre o combate ao assédio e à violência doméstica. São casos como o da advogada Tatiane Spitzner $^{1}$ e do falso motorista de aplicativo acusado de recorrentes estupros na cidade de Fortaleza ${ }^{2}$. O que esses casos têm em comum é que a violência é perceptível, não admitida por uma grande parcela da sociedade, mas há muito mais o que se pensar por trás dessas violações.

Segundo os Relógios da Violência (INSTITUTO MARIA DA PENHA, 2017), no Brasil, a cada 2 segundos uma mulher é vítima de violência física ou verbal e a cada 1,4 segundos uma mulher é vítima de assédio. Esses dados refletem a violência visível, mais facilmente reconhecida pelas vítimas e pelos agressores, menos naturalizada e relativizada, ainda que subsista a culpabilização da mulher, mais pesquisada e mais debatida.

De acordo com pesquisa do Fórum Brasileiro de Segurança Pública em parceira com a Datafolha (2017), 73\% da população brasileira acredita que a violência contra a mulher aumentou nos últimos 10 anos. Essa percepção é influenciada, em grande parte, pela maior conscientização das mulheres, principalmente, sobre as diversas formas opressão e violações perpetradas pelos homens diariamente. Condutas que antes eram naturalizadas, hoje são tidas como expressões agressivas, persistindo, então, as formas de violência tradicionalmente combatidas, como a agressão física, mas também modos de opressão que antes eram normais, como o assédio na rua e no transporte público.

\footnotetext{
${ }^{1}$ Tatiane Spitzner foi encontrada morta após uma queda do quarto andar do prédio em que morava com o marido no Paraná. Em momento anterior a queda, as câmeras internas do prédio registraram uma série de agressões físicas perpetradas pelo marido, suspeito de feminicídio (VEJA, 2018).

${ }^{2}$ Falso motorista de aplicativo de transporte foi acusado por quatro casos de estupro. O motorista, que fraudava as contas usando documentos de outras pessoas, pegou as vítimas pelo aplicativo e levou-as até uma região isolada onde ameaçou, filmou e violentou-as sexualmente (O POVO, 2018).
} 
No entanto, mesmo que tenha aumentado a percepção das mulheres sobre as violências diárias por elas enfrentadas, ainda se discute pouco sobre a origem dessas violações, sobre a reprodução de discursos e de práticas que passam despercebidas, sobre as chamadas violências simbólicas.

Pode-se definir a violência simbólica como uma série de condutas que não atingem a vítima de forma física e nem mesmo se orientam no sentido de atingir especificamente apenas uma mulher, mas que geram abalos morais e psicológicos, situações que geram desconforto social às vítimas na reprodução de uma cultura machista. A violência simbólica se apresenta, muitas vezes, em ações do cotidiano que acabam por reproduzir uma lógica de inferiorização da mulher, a título de exemplo podemos citar situações nas quais sempre é esperado que o homem tenha uma renda maior que a sua companheira, que o homem exerça o papel de chefe e líder da família, que o corpo da mulher esteja sempre à disposição do seu companheiro independente das suas vontades.

O desconhecimento e a falta de consciência sobre a violência simbólica são latentes na sociedade, que segue reproduzindo discursos estereotipados e piadas machistas, principalmente visualizadas nas ações masculinas. Os homens seguem tomando espaços políticos e de fala, relegando às mulheres atividades estruturais, interrompendo, relativizando os discursos, tratando a mulher como menos racional, consciente e preparada para lidar com diversas questões. Essa realidade é bem visualizada na pesquisa "Percepções dos homens sobre a violências doméstica contra a mulher" (2013) realizada pelo Instituto Avon. Segundo a pesquisa, apenas $16 \%$ dos entrevistados admitem já terem praticado alguma violência contra a companheira, no entanto, $85 \%$ consideram inaceitável que uma mulher fique bêbada, $69 \%$ não admitem que a companheira saia com os amigos sozinha, $89 \%$ acredita que é inadmissível que a mulher não mantenha a casa em ordem e 53\% acredita que a responsabilidade de manter o casamento é da mulher. Além disso, $48 \%$ não acha correto a mulher procurar ajuda policial se o marido a obrigar a fazer sexo sem vontade, $35 \%$ se ela for humilhada em público e $31 \%$ se ela for impedida de sair.

Diante disso, é possível perceber que a violência simbólica contra a mulher é resultado de uma estrutura de dominação e, por esse motivo, está presente em todos os espaços ocupados por mulheres. Por mais que os homens nos projetos e coletivos sejam contra a violência de gênero, por fazerem parte de uma construção social incisiva, acabam reproduzindo discursos e práticas que invisibilizam e oprimem as mulheres. 
Dessa forma, os espaços auto-organizados surgem como uma alternativa para fortalecer os laços entre as mulheres na luta contra as opressões dentro dos espaços que elas desenvolvem atividades, principalmente no âmbito da universidade, das organizações políticas e do movimento estudantil. Esses espaços são importantes para que as mulheres, que sofrem as violações, compartilhem as vivências, tenham liberdade para falar de questões que as atingem, sejam empoderadas e visualizem estratégias para levar esses debates para a organização mista. Ademais, os espaços auto-organizados dentro dos projetos e movimentos propiciam que as ações ultrapassem a dimensão dos núcleos e sejam implementadas em um nível mais amplo.

Nesse contexto, foi criada a Plenária de Mulheres do Centro de Assessoria Jurídica Universitária (CAJU), programa de extensão ao qual está vinculado o projeto Diálogos para Diversidade. O CAJU é uma assessoria jurídica universitária, que reivindica a prática de uma extensão popular e, portanto, sempre esteve associado a pautas de direitos humanos, emancipação dos sujeitos e combate às opressões de classe e gênero. No entanto, mesmo dentro do núcleo, havia a percepção da violência simbólica e da reprodução de práticas machistas que ensejaram a criação de um espaço organizado apenas por mulheres onde estas pudessem debater e construir suas lutas coletivas.

Isto posto, a presente pesquisa visa analisar as ações desenvolvidas pelo projeto Diálogos para Diversidade a partir das ações de extensão organizadas pela Plenária de Mulheres do CAJU. Objetiva, ainda, refletir sobre a importância dos espaços auto-organizados de mulheres para o combate ao machismo e à violência simbólica dentro e fora dos núcleos e contribuir para o fortalecimento das lutas femininas cotidianas.

\section{REFERENCIAL TEÓRICO}

\subsection{VIOLÊNCIA SIMBÓliCA E A IMPORTÂNCIA DOS ESPAÇOS AUTO- ORGANIZADOS NA EXTENSÃO POPULAR}

Como falado anteriormente, muitas das dificuldades enfrentadas pelas mulheres em diversos espaços, entre eles a extensão popular, decorrem de uma violência simbólica, que muitas vezes é invisível às próprias vítimas por ser uma situação já naturalizada socialmente. Para Silva e Oliveira (2017):

A violência simbólica se funda na fabricação contínua de crenças no processo de socialização, que induzem o indivíduo a se posicionar no espaço social 
seguindo critérios e padrões do discurso dominante. Devido a esse conhecimento do discurso dominante, a violência simbólica é manifestação desse conhecimento através do reconhecimento da legitimidade desse discurso dominante. Para Bourdieu, esta opressão específica é o meio de exercício do poder simbólico. O dominado não se opõe ao seu opressor, já que não se percebe como vítima deste processo: ao contrário, o oprimido considera a situação natural e inevitável (SILVA; VIEIRA, 2017, p.6-7).

Esse poder simbólico é expresso por estruturas comunicativas e culturais, pela língua, pela arte e pela religião, denominadas por Bourdieu de sistemas simbólicos. O poder simbólico é, portanto, estruturado historicamente, através de discursos religiosos e até mesmo científicos que tratam como ordem natural a ocupação de espaços privados pelas mulheres e espaços públicos pelos homens. Segundo preleciona Rachel Soihet (1997):

Tais teorias construídas e instauradas por homens que estabelecem um duplo discurso, do homem sobre o homem e do homem sobre a mulher, restritivas da liberdade e da autonomia feminina, que convertem uma relação de diferença numa hierarquia de desigualdade, configuram uma forma de violência. As mulheres tratadas não como sujeito, mas como uma coisa, buscando-se impedir a sua fala e a sua atividade. Nesta perspectiva, a violência não se resume a atos de agressão física, decorrendo igualmente, de uma normatização na cultura, da discriminação e submissão feminina. Aliás, o avanço do processo de civilização, entre os séculos XVI e XVII, corresponderia a um recuo da violência bruta, substituindo-se os enfrentamentos corporais por lutas simbólicas. Nesse período, a construção da identidade feminina se pautaria na interiorização pelas mulheres das normas enunciadas pelos discursos femininos; fato correspondente a uma violência simbólica que supõe a adesão dos dominados às categorias que embasam sua dominação. (SOIHET, 1997, p.10)

Dessa forma, a violência simbólica está presente nos discursos e nas práticas cotidianas, porém, por fazer parte de uma estrutura de dominação, não é percebida e, mais que isso, é naturalizada como uma conduta normal e que não traz maiores implicações para as mulheres. No entanto, cabe visualizar que a violência contra a mulher se estrutura em uma pirâmide, que tem em sua base a violência simbólica. A proliferação de discursos machistas, que invisibilizam e estereotipam as mulheres e as colocam em posição inferior, são o fundamento para legitimar a ocorrência das agressões mais graves, como a violência física e sexual.

Questiona-se, então, já que se trata de um tipo de violência muito nociva, mas de expressão sutil, de que forma esse ciclo pode ser quebrado. Como alternativa, propõe-se que apenas quando os sujeitos oprimidos estiverem suficientemente fortalecidos para reconhecer e combater a violência simbólica, existe a possibilidade de modificar esse cenário. Os espaços auto-organizados surgem nessa perspectiva de acolher e fortalecer esses sujeitos.

Na prática dos núcleos de Assessoria Jurídica Universitária Popular (AJUP), modo de extensão popular no qual o CAJU exerce suas atividades, é sempre buscado um ideal de horizontalidade, um dos princípios norteadores da prática da AJUP, no qual objetiva-se que 
todos os membros do projeto tenham níveis de participação os mais similares possíveis, que as opiniões de todos sejam levadas em consideração na construção das ações coletivas. Como desenvolvem Barbosa e Vieira (2017):

Nessa perspectiva, muitos núcleos de AJUP procuram a ausência de hierarquia entre os membros, a inexistência de um líder ou de alguém que possua funções mais importantes. Há uma predileção pela tomada de decisões em conjunto, evitando a centralização de tarefas. (BARBOSA; VIEIRA, 2017, p.4)

Entretanto, quando se parte de uma realidade na qual as pessoas não podem desfrutar dos mesmos direitos e sofrem diferentes formas de opressão, a efetivação da horizontalidade se torna um desafio. Mesmo que os membros do projeto compartilhem do ideal de que todas as formas de opressão contribuem para um mundo mais injusto e desigual e de que elas devem ser abolidas, é difícil não reproduzir algumas práticas já tão normalizadas socialmente, algumas dessas ações, não são sequer reconhecidas como ofensivas por quem as pratica.

Situações como homens concentrarem discussões políticas entre si enquanto relegam tarefas estruturais e de organização para as mulheres ou homens serem sempre tidos como indispensáveis para qualquer ação ou tomada de decisão do núcleo, são encaradas muitas vezes como naturais. Assim, percebeu-se que se o núcleo continuasse na mesma dinâmica essas opressões continuariam sendo reproduzidas e os membros que as sofriam nunca se sentiriam confortáveis para objetá-las.

É nesse ponto que se justifica a criação de espaços auto-organizados, que consistem em uma articulação da qual participam apenas sujeitos que sofrem determinado tipo de opressão, pois objetivam o fortalecimento desses sujeitos sociais que historicamente não têm a abertura para participarem politicamente da construção dos espaços, para que possam adquirir segurança para expor seus pensamentos e lutar contra a invisibilização que os atinge. É um espaço entendido como seguro para que esses sujeitos possam relatar as situações de opressão que passaram dentro do núcleo e juntos pensarem em ações, tanto de fortalecimento, quanto de enfrentamento dessas opressões no espaço misto.

Segundo relatos colhidos a partir da pesquisa realizada por Gabriela de Almeida Furtado (2017) no âmbito da assessoria jurídica NAJUC JA (Núcleo de Assessoria Jurídica Comunitária Justiça e Atitude), a auto-organização no núcleo trouxe o empoderamento das mulheres, que passaram a ocupar os espaços políticos com maior segurança e propriedade, assim como, possibilitou que as práticas e os discursos machistas fossem percebidos com mais facilidade, tanto dentro como fora do núcleo, inclusive na advocacia tradicional. A revelia dos questionamentos iniciais sobre a iniciativa "dividir o núcleo e a luta”, a auto-organização das 
mulheres do NAJUC JA se concretizou numa efetivação dos direitos humanos das mulheres do núcleo e da educação popular, um dos fundamentos da assessoria jurídica popular, a partir do momento em que se converteu na prática educativa e transformadora pensada por Paulo Freire (FURTADO, 2017, p.51-64).

Ademais, os espaços auto-organizados são importantes como forma de fortalecer as relações entre as mulheres nos núcleos de assessoria jurídica universitária. A aproximação de laços estimula a sororidade e o apoio mútuo, desenvolvendo uma maior compreensão sobre as opressões de classe e de raça. Dessa forma, os debates sobre intersecções são inseridos dentro das discussões das auto-organizações de mulheres e fomentam a reflexão crítica sobre o feminismo e suas demandas individuais e coletivas.

Por fim, pela experiência da Plenária de Mulheres do CAJU, a auto-organização confere uma autonomia às mulheres, que, reconhecendo-se como sujeitos políticos, passam a desenvolver ações sem a interferência dos demais membros do núcleo. Em um movimento contínuo, a Plenária de Mulheres desenvolve atividades paralelas às lutas tradicionais das assessorias jurídicas populares, que consistem no acompanhamento dos movimentos populares e comunidades, para pensar a sobrevivência e a permanência das mulheres no ambiente universitário, compreendendo que nenhuma dessas lutas serão desempenhadas se as mulheres não se sentirem acolhidas, empoderadas e fortalecidas para estarem na linha de frente das assessorias jurídicas.

\subsection{HISTÓRICO DA PLENÁRIA DE MULHERES DO CENTRO DE ASSESSORIA JURÍDICA UNIVERSITÁRIA (CAJU)}

A Plenária de Mulheres foi organizada, no formato de um espaço coletivo de debates, pela primeira vez no dia 06 de julho de 2013, coincidentemente na data em que nasceu Frida Khalo, símbolo da resistência feminina na vida e nas artes. Puxado pelas meninas do CAJU, o espaço tinha como objetivo discutir as formas de opressão contra as mulheres, debatendo os discursos e práticas que eram reproduzidos dentro dos projetos de extensão, da Faculdade de Direito e da Universidade como um todo.

A ideia da Plenária de Mulheres surgiu com a participação do CAJU no ERENAJU (Encontro da Rede Nacional de Assessoria Jurídica Universitária), em 2013. As mulheres que faziam parte do núcleo participaram de um espaço auto-organizado dentro da programação do 
Encontro e, a partir de então, perceberam que as mulheres das demais assessorias espalhadas pelo país começavam a se organizar em espécies de setoriais ou coletivos que tinham como objetivo debater o combate ao machismo dentro das assessorias jurídicas. Apesar de compreender a dimensão da violência de gênero e a necessidade do combate ao patriarcado, os homens que participavam das assessorias jurídicas populares, por questões sociais e históricas, reproduziam práticas e discursos da lógica patriarcal, silenciando e cortando a fala das mulheres, ocupando prioritariamente espaços políticos de militância e de atuação nas comunidades, escolhendo as linhas de atuação dos projetos.

Ao perceber a repetição dessa estrutura dentro do CAJU, as mulheres organizaram-se para pautar isso dentro de um coletivo. O Coletivo Feminista Lilas nasceu da primeira Plenária de Mulheres do CAJU e se expandiu para além da Faculdade de Direito, transformando-se numa organização que agregava também meninas de outros cursos da Universidade Federal do Ceará (UFC). O nome Lilas tem origem na figura de Lila Beserra, mulher cearense, negra e lésbica que, durante as manifestações em junho de 2013, foi detida e agredida pela Polícia. O nome Lilas remete também a cor dos movimentos feministas.

O Coletivo Feminista passou a trabalhar com diversas demandas das mulheres da UFC, mas aos poucos foi se desarticulando e as Lilas pararam de atuar. Permaneceu, porém, a Plenária de Mulheres do CAJU como um espaço permanente dentro do núcleo para fortalecer os laços entre as mulheres e o debate sobre feminismo, reivindicar dentro do CAJU que a mulheres sejam respeitadas e não sejam excluídas das atividades, debater a questão de gênero e com autonomia para organizar ações de extensão voltadas ao combate ao machismo e à violência contra a mulher na Faculdade de Direito.

\subsection{AS AÇÕES DE EXTENSÃo DESENVOLVIDAS PELA PLENÁRIA DE MULHERES DE 2017 A 2018}

A Plenária de Mulheres, então, visualizando que a reprodução de práticas e discursos que invisibilizam, objetificam e violam os direitos das mulheres são violências cotidianas e compreendendo a importância das mulheres construírem debates, passou a pensar atividades que levassem a discussão do grupo para um público maior. Desde o nascimento, como apontado anteriormente, a Plenária não tinha como objetivo restringir suas atividades ao interior do núcleo, mas colocar as temáticas feministas para espaços onde pudessem ser compartilhadas 
com outras mulheres, mesmo de fora das assessorias, que convivem diariamente com a opressão.

Com essa concepção, a Plenária de Mulheres produziu, durante o ano de 2017, uma Cartilha sobre Assédio. O objetivo da cartilha é conceituar juridicamente o assédio sexual e as outras formas de assédio não tipificadas, abordando como esse comportamento atinge as mulheres nos mais diversos âmbitos, no trabalho, na universidade, na internet, na rua e no ambiente privado, assim como dar orientações de onde procurar ajuda policial, social, psicológica e jurídica em casos de violência contra a mulher.

A iniciativa de produção da Cartilha surgiu em reuniões da plenária nas quais as mulheres do núcleo conversavam sobre temáticas como relacionamentos abusivos e compartilhavam seus relatos sobre as vivências na Universidade. Percebendo que essa era uma realidade que necessidade de debate e de orientação, as mulheres da Plenária organizaram a atividade e utilizam a cartilha em diversas outras ações do grupo. A Cartilha foi lançada em novembro de 2017 durante um Cine Plenária.

O Cine Plenária é uma outra atividade desenvolvida pela Plenária de Mulheres do CAJU, normalmente no segundo semestre do ano, no qual é exibido um filme que traga temáticas relacionadas à mulher acompanhado de um posterior debate sobre esse tema. O Cine de lançamento da Cartilha contou com a exibição do documentário Precisamos Falar do Assédio (2016), produzido por um projeto homônimo, que traz os depoimentos de 26 mulheres sobre os abusos vivenciados por elas.

O filme exibido conta com uma perspectiva intimista, os depoimentos foram colhidos na semana da mulher, entre os dias 07 a 14 de março de 2016, nas cidades de São Paulo e Rio de Janeiro, por uma van-estúdio, que passou por nove lugares, e relatados em formato de desabafo, sem intervenção de um outro sujeito. As mulheres que prestaram seus depoimentos podiam não se identificar, escolhendo máscaras disponibilizadas pelos produtores que refletiam quatro sentimentos: vergonha, medo, raiva ou tristeza. A perspectiva trazida pelo filme foi essencial para despertar a real necessidade de se discutir essa temática. O debate, após a exibição do filme, foi facilitado por antigas participantes do CAJU e, portanto, da Plenária de Mulheres, levantando diversas questões relevantes sobre o tema.

No início de 2018, a Plenária continuou a implementar ações voltadas para fora do núcleo. Em virtude da proximidade das eleições nacionais e compreendendo a importância de fomentar a ocupação dos espaços públicos por mulheres e de falar sobre mulheres para além do 
mês de março, a Plenária organizou uma campanha virtual para resgatar e celebrar as mulheres que ocuparam ou ocupam lugares na política institucional do país. As mulheres foram escolhidas pela Plenária intercalando figuras históricas e importantes na luta das mulheres.

A campanha contou com postagens semanais na página do projeto trazendo figuras femininas protagonistas nas suas lutas contra o sistema patriarcal que impede as mulheres de ocuparem o poder político. Foram realizadas postagens sobre Maria Luiza Fontenele, prefeita da cidade de Fortaleza em 1985 e primeira mulher a assumir o poder executivo no Brasil; a deputada Benedita da Silva, que ocupa uma posição de destaque na defesa dos Direitos Humanos na Câmara de Deputados; Talíria Petrone, vereadora mais votada para a Câmara Municipal de Niterói e única mulher a integrar o corpo de vereadores da cidade; Leolinda Figueiredo, pioneira na luta pelo voto feminino no Brasil; e Kátia Tapety, primeira travesti eleita para um cargo político no país.

Ademais, pensando ainda em ações que tragam a temática do assédio na universidade, a Plenária de Mulheres criou a iniciativa, que ainda está em desenvolvimento, de uma caixinha que está à disposição das alunas para colher casos de assédio moral e sexual no âmbito da Faculdade de Direito da Universidade Federal do Ceará (UFC). A caixinha tem o objetivo de visualizar a dimensão dessa violência na Faculdade, compreender o porquê de muitos casos não serem denunciados, além de fornecer, se necessário, ajuda para solucionar esses casos. Os dados serão obtidos tanto através da caixinha como por meio de formulário online, de forma a acolher o maior número possível de mulheres para falarem sobre o tema, e subsidiarão a produção de um relatório sobre o assédio moral e sexual na Faculdade de Direito.

Por fim, como dimensão mais interna da organização, são realizados os grupos de estudo abertos, onde são debatidas temáticas relacionadas ao feminismo, violência contra a mulher e intersecção. No ano de 2018, os grupos de estudo têm abordado o livro Mulheres, Classe e Raça de Angela Davis, que inaugura questões referentes a intersecções de raça dentro dos movimentos feministas e da luta das mulheres por libertação.

\section{MATERIAIS E MÉTODOS}

Para o desenvolvimento do trabalho utiliza-se a pesquisa bibliográfica, com a revisão de obras, prioritariamente de autoras feministas, sobre a conceituação de violência simbólica e o combate às formas de opressão, além da utilização de dados e de pesquisas quantitativas já realizadas. Emprega-se, também, a observação participante, através do relato e da análise das 
ações de extensão desenvolvida pela Plenária de Mulheres e do impacto das atividades na organização do núcleo e na Faculdade de Direito da Universidade Federal do Ceará (UFC).

Dessa forma, o trabalho inicia analisando as formas de opressão de gênero presentes na sociedade, conceituando a violência simbólica e buscando compreender como esse modo de violação contribui para a criação de uma pirâmide de violência contra a mulher que culmina em agressões mais severas. Em um segundo momento, é apresentada a história da criação e da organização da Plenária de Mulheres no âmbito do CAJU. Ademais, em um terceiro ponto, são relatadas e avaliadas as ações de extensão desenvolvidas pela Plenária entre 2017 e 2018.

\section{RESULTADOS E DISCUSSÕES}

A violência contra a mulher é uma prática cotidiana de inferiorização, invisibilização e violação da condição e dos direitos fundamentais das mulheres. A violência é marcante e facilmente visualizada quando atinge proporções de agressão física, estupro, violência doméstica, mas constantemente negligenciada quando se reproduz em práticas e discursos naturalizados que colocam a mulher em posição de culpa, de irracionalidade, de incapacidade e as afastam dos espaços públicos, isto é, a chamada violência simbólica.

A violência simbólica, apesar de, na maioria das vezes, ser tomada como insignificante, é o fundamento de uma estrutura de violência que se organiza em pirâmide, culminando nas violências perceptíveis. A violência simbólica é uma violência cultural, transmitida e reproduzida de forma sutil em todos os espaços ocupados por mulheres, seja na rua, no âmbito familiar ou na universidade.

Nessa perspectiva, os espaços auto-organizados surgem como uma alternativa para combater as práticas e ações machistas dentro dos projetos e dos movimentos sociais, desenvolvendo um importante papel no fortalecimento da luta das mulheres, no empoderamento, na ocupação dos espaços políticos e na promoção de ações que visem levar os debates para além das organizações.

Os espaços auto-organizados são, assim, estruturas essenciais na prática da assessoria jurídica universitária, que apesar de tradicionalmente associada à luta pelos direitos humanos e reivindicando a extensão popular, reproduz estruturas sociais historicamente construídas. As atividades dos espaços fomentam a horizontalidade e a extensão popular, princípios da 
assessoria jurídica popular, assim como conferem maior autonomia feminina, a partir do momento que possibilita o desenvolvimento de ações de extensão.

\section{CONCLUSÃO}

Na perspectiva da Plenária de Mulheres do CAJU, a atuação se deu, principalmente lidando com a questão do assédio moral e sexual, estendendo-se para além do núcleo e levando o debate para outras mulheres que sofrem as mesmas condições diariamente. As atividades desenvolvidas pelas Plenária, ainda que não sejam grandes ações, contam como um trabalho importante no meio social e universitário, tendo em vista a urgência de se pautar e debater tais temas e combater todos os tipos de violência contra a mulher.

Pode-se concluir, portanto, que a criação de espaços auto-organizados é fundamental para estender a atuação dos núcleos de assessoria jurídica universitária, além de fornecer um espaço para que a mulheres se sintam livres, acolhidas e empoderadas para ocupar politicamente os lugares e desenvolver as atividades dos projetos. Ademais, a prática permite que as temáticas e os debates sejam compartilhados com as mais diversas mulheres que sofrem os mais diversos tipos de violência diariamente, fortalecendo-as também para lutar contra um sistema patriarcal e machista que nega à mulher o espaço público, seu corpo e seus direitos.

\section{REFERÊNCIAS}

BARBOSA, Guilherme Bezerra; VIEIRA, Larissa Camurça. Assessoria jurídica universitária popular e os processos de tomada de decisões acerca dos instrumentos de política urbana em âmbito municipal. Brazilian Applied Science Review. Curitiba, v. 2, n. 1, p.291-304, jan/mar 2018. Disponível em: <http://www.brjd.com.br/index.php/BASR/article/view/380/324>. Acesso em 01 de setembro de 2018.

DATAFOLHA; FÓRUM DE SEGURANÇA PÚBLICA, 2017. Visível e invisível: a vitimização de mulheres no Brasil. Disponível em: <http://www.forumseguranca.org.br/wpcontent/uploads/2017/03/relatorio-pesquisa-vs4.pdf>. Acesso em 01 de setembro de 2018.

FURTADO, Gabriela de Almeida. Maria vai com as outras: a auto-organização de mulheres do Núcleo de Assessoria Jurídica Comunitária Justiça e Atitude (NAJUC JA) enquanto promoção de educação popular em direitos humanos. 2017. 85 f. TCC (Graduação) - Curso de Direito, Instituto de Ciências Jurídicas e Sociais Prof. Camillo Filho, Teresina, 2017.

INSTITUTO AVON. Percepções do homem sobre a violência doméstica contra mulher, 2013. Disponível em: <http://www.compromissoeatitude.org.br/wp- 
content/uploads/2013/12/folderpesquisa_instituto22x44_5.pdf>. Acesso em 01 de setembro de 2018.

INSTITUTO MARIA DA PENHA. Relógios da Violência, 2018. Disponível em: <https://www.relogiosdaviolencia.com.br/\#>. Acesso em 01 de setembro de 2018.

SILVA, L. F., OLIVEIRA, L.. Rev. FSA. Teresina, v. 14, n.3, art. 9, p. 160-174, mai./jun. 2017. Disponível em: <http://www4.fsanet.com.br/revista/index.php/fsa/article/view/1342/1249>. Acesso em 01 de setembro de 2018.

O POVO. Falso motorista de app é preso acusado de quatro casos de estupro. Disponível

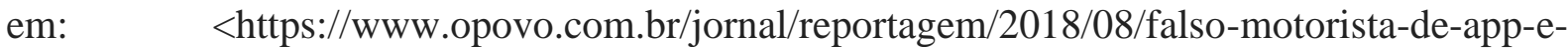
investigado-por-4-casos-de-estupro.html>. Acesso em 02 de setembro de 2018.

SOIHET, Rachel. Violência Simbólica: Saberes Masculinos e Representações femininas. Estudos Feministas, Florianópolis, v. 5, n. 1, p.7-29, jan/abr, 1997.

VEJA. Câmeras mostram marido agredindo advogada que caiu de prédio. Disponível em: $<$ https://veja.abril.com.br/blog/parana/cameras-mostram-marido-agredindo-advogada-quecaiu-de-predio/>. Acesso em 02 de setembro de 2018. 